Article

\title{
Contamination Effects on Improving the Hydrogenation/Dehydrogenation Kinetics of Binary Magnesium Hydride/Titanium Carbide Systems Prepared by Reactive Ball Milling
}

\author{
M. Sherif El-Eskandarany * and Ehab Shaban
}

Received: 18 August 2015 ; Accepted: 15 September 2015 ; Published: 10 October 2015

Academic Editor: Jordi Sort

Nanotechnology and Advanced Materials Program, Energy and Building Research Center, Kuwait Institute for Scientific Research, Safat 13109, Kuwait; eshaaban@kisr.edu.kw

* Correspondence: msherif99@yahoo.com

\begin{abstract}
Ultrafine $\mathrm{MgH}_{2}$ nanocrystalline powders were prepared by reactive ball milling of elemental $\mathrm{Mg}$ powders after $200 \mathrm{~h}$ of high-energy ball milling under a hydrogen gas pressure of 50 bar. The as-prepared metal hydride powders were contaminated with $2.2 \mathrm{wt}$. \% of FeCr-stainless steel that was introduced to the powders upon using stainless steel milling tools made of the same alloy. The as-synthesized $\mathrm{MgH}_{2}$ was doped with previously prepared $\mathrm{TiC}$ nanopowders, which were contaminated with $2.4 \mathrm{wt}$. \% FeCr (materials of the milling media), and then ball milled under hydrogen gas atmosphere for $50 \mathrm{~h}$. The results related to the morphological examinations of the fabricated nanocomposite powders beyond the micro-and nano-levels showed excellent distributions of $5.2 \mathrm{wt}$. \% $\mathrm{TiC} / 4.6 \mathrm{wt}$. \% $\mathrm{FeCr}$ dispersoids embedded into the fine host matrix of $\mathrm{MgH}_{2}$ powders. The as-fabricated nanocomposite $\mathrm{MgH}_{2} / 5.2$ wt. \% TiC/4.6 wt. \% FeCr powders possessed superior hydrogenation/dehydrogenation characteristics, suggested by the low value of the activation energy $(97.74 \mathrm{~kJ} / \mathrm{mol})$, and the short time required for achieving a complete absorption $(6.6 \mathrm{~min})$ and desorption $(8.4 \mathrm{~min})$ of $5.51 \mathrm{wt} . \% \mathrm{H}_{2}$ at a moderate temperature of $275{ }^{\circ} \mathrm{C}$ under a hydrogen gas pressure ranging from 100 mbar to 8 bar. van't Hoff approach was used to calculate the enthalpy $(\Delta H)$ and entropy $(\Delta S)$ of hydrogenation for $\mathrm{MgH}_{2}$, which was found to be $-72.74 \mathrm{~kJ} / \mathrm{mol}$ and $112.79 \mathrm{~J} / \mathrm{mol} \mathrm{H}_{2} / \mathrm{K}$, respectively. Moreover, van't Hoff method was employed to calculate the $\Delta \mathrm{H}$ and $\Delta \mathrm{S}$ of dehydrogenation, which was found to be $76.76 \mathrm{~kJ} / \mathrm{mol}$ and $119.15 \mathrm{~J} / \mathrm{mol} \mathrm{H}_{2} / \mathrm{K}$, respectively. This new nanocomposite system possessed excellent absorption/desorption cyclability of 696 complete cycles, achieved in a cyclic-life-time of $682 \mathrm{~h}$.
\end{abstract}

Keywords: reactive ball milling; grain-growth inhibitors; $\mathrm{FeCr}$ contamination; hydrogen storage nanocomposites; kinetics; cycle-life-time

\section{Introduction}

Hydrogen storage is one of the key enabling technologies for realization of hydrogen energy economy [1]. Hydrogen storage materials, taking metal hydrides as a typical example, are commercially prepared by solvent-based synthesis methods or by direct gas-solid hydrogenation reactions. In contrast to the traditional gas-solid hydrogenation process, which is achieved at temperatures far above room temperature, an attractive method-so-called reactive ball milling (RBM) [2,3]—was developed in the 1990s to conduct the exothermic reactions between the gas- and metallic solid phases at almost room temperature. This relatively new process has been considered as 
a powerful tool for fabrication of different nanocrystalline metallic nitrides and hydrides [4]. In their room-temperature process, the starting metallic powders are subjected to dramatic shear and impact forces generated by the milling media (balls). The powders are, therefore, disintegrated into smaller particles with large surface area, and very clean or fresh oxygen-free active surfaces of the powders are created. The reactive milling atmosphere (nitrogen or hydrogen gases) was gettered and absorbed completely by the first atomically clean surfaces of the metallic ball-milled powders to react in a same manner as a typical gas-solid reaction [5]. Since then, the RBM process has become a common technique successfully used for preparing nanocrystalline metal hydrides, including magnesium hydride $\left(\mathrm{MgH}_{2}\right)$ and their composite powders [1,6].

High capacity hydrogen storage materials such as $\mathrm{MgH}_{2}$ have been receiving much attention as promising solid-state hydrogen storage systems due to their high hydrogen storage capacity (7.60 wt. \%), reversibility, cost effectiveness, availability and cyclability [7-9]. The international interest in the development of hydrogen based technologies, particularly the area of fuel cell electric vehicles, has greatly increased in recent years [9].

Unfortunately, and in contrast to the obvious advantages seen in $\mathrm{MgH}_{2}$ binary hydrogen storage systems, the high thermal stability and the difficulty to decompose this hydride system into metal and hydrogen gas, plus the poor hydrogenation and consequence dehydrogenation kinetics, lead to restricting utilization of such a light-weight system in real automobile applications [7,9,10].

Even though and in spite of the serious drawbacks found in $\mathrm{MgH}_{2}$, the worldwide interest in such an attractive binary metal hydride has been increased, especially after improving its hydrogen absorption and desorption kinetics by applying a longer ball milling time that led to destabilizing the $\beta-\mathrm{MgH}_{2}$ phase and increasing the volume fractions of the metastable $\gamma-\mathrm{MgH}_{2}$ phase [11]. Long mechanical ball milling time always is one key approach for releasing the crystalline stored energy, leading to refining the $\mathrm{MgH}_{2}$ grains along their grain boundaries resulting in a fine-grained structure. Such fine grains with their short-distance grain boundaries always facilitate a short diffusion path, allowing fast diffusion of the hydrogen atoms into the $\mathrm{Mg}$ lattice [12].

Moreover, ball milling the $\mathrm{MgH}_{2}$ with pure metallic catalysts (e.g., $\mathrm{Ti}, \mathrm{Fe}, \mathrm{Ni}, \mathrm{Nb}, \mathrm{V}$ ) [13], intermetallic compounds (e.g., $\mathrm{Zr}_{100-x} \mathrm{Ni}_{x}$, and Ti-based alloys) [14-16], metal carbides such as $\mathrm{TiC}$ [17], metal oxides such as $\mathrm{Nb}_{2} \mathrm{O}_{5}$ [18], metal chlorides such as $\mathrm{MgCl}_{2}$ [19], rare earth chlorides such as $\mathrm{LaCl}_{3}$ [20], and nanocomposite $\mathrm{Ni} / \mathrm{Nb}_{2} \mathrm{O}_{5}$ powders [21] led to remarkable improvement in the hydrogen absorption/desorption kinetics and lowering the thermal stability of $\mathrm{MgH}_{2}$. It has been shown by Ismail [20] that the improved hydrogen storage properties of $\mathrm{MgH}_{2}$ doped with $\mathrm{LaCl}_{3}$ were due to the catalytic effects of the La-Mg alloy and $\mathrm{MgCl}_{2}$. Such ultrafine micro-scaled/nano-scaled powders serving as catalysts have shown the possibility of improving the hydrogenation/dehydrogenation properties of $\mathrm{MgH}_{2}$ to open up a new horizon for its real application.

In the present study, we have investigated the effect of $\mathrm{FeCr}$ contamination introduced to the $\mathrm{MgH}_{2}$ powders upon ball milling in the long term on improving the hydrogenation/dehydrogenation properties of the metal hydride phase. Moreover, the effect of doping the as-synthesized $\mathrm{MgH}_{2}$ nanocrystalline powders with $\mathrm{TiC}$ nanopowders on the hydrogen storage capacity and cyclability of $\mathrm{MgH}_{2}$ was studied in terms of morphology and kinetics.

\section{Experimental Procedure}

Pure Mg metal powders ( $~ 80 \mu \mathrm{m}, 99.8 \%$ purity provided by Alfa Aesar - Ward Hill, MA, USA), synthesized $\mathrm{TiC}$ nanopowders obtained upon high-energy ball milling of $\mathrm{Ti}$ and graphite powder ( 100 nm, 2.4 wt. \% FeCr), and hydrogen gas (99.999\%) were used as starting materials. A certain amount of the $\mathrm{Mg}$ powders (5 g) was balanced inside a helium (He) gas atmosphere (99.99\%)—glove box (UNILAB Pro Glove Box Workstation, mBRAUN, Garching, Germany). The powders were then sealed together with $50 \mathrm{FeCr}$ - stainless steel balls into a $\mathrm{FeCr}$ steel vial ( $220 \mathrm{~mL}$ in volume), using a gas-temperature-monitoring system (GST; supplied by evico magnetic, Dresden, Germany). The 
ball-to-powder weight ratio was 40:1. The vial was then evacuated to the level of $10^{-3}$ bar before introducing $\mathrm{H}_{2}$ gas to fill the vial with a pressure of 50 bar. The milling process was carried out at room temperature using high energy ball mill (Planetary Mono Mill PULVERISETTE 6, Fritsch, Idar-Oberstein, Germany). After $200 \mathrm{~h}$ of RBM, the powders were discharged from the vial inside the glove box and sealed into two Pyrex vials. The as-synthesized $\mathrm{MgH}_{2}$ powders were then mixed in the glove box with the desired weight percentage $(5 \%)$ of $\mathrm{TiC}$, using an agate mortar and pestle. Five gram of the mixed powders were charged together with 50 hardened steel balls into the hardened steel vial and sealed under He gas atmosphere [21]. The vial was then filled with 50 bar of hydrogen gas atmosphere and mounted on the high-energy ball mill. The milling process was interrupted after selected time $(25$, and $50 \mathrm{~h})$ and the powders obtained after an individual milling time were completely discharged into 8 Pyrex vials for different analyses. The average crystal structure of all samples was investigated by X-ray diffraction (XRD) with $\mathrm{CuK} \alpha$ radiation, using $9 \mathrm{~kW}$ Intelligent $X$-ray diffraction system, provided by SmartLab-Rigaku, Tokyo, Japan. The local structure of the synthesized material powders at the nanoscale was studied by $200 \mathrm{kV}$-field emission high resolution transmission electron microscopy/scanning transmission electron microscopy (HRTEM/STEM) supplied by JEOL-2100F, Tokyo, Japan, equipped with Energy-dispersive X-ray spectroscopy (EDS) supplied by Oxford Instruments, Oxfordshire, UK. The morphological properties of the powders after selected ball milling times were determined by $15 \mathrm{kV}$-field emission scanning electron microscope (FE-SEM, JSM-7800F, Tokyo, Japan) equipped with EDS supplied by Oxford Instruments, UK. The concentrations of elemental $\mathrm{Mg}$, $\mathrm{Ti}, \mathrm{Fe}$, and $\mathrm{Cr}$ in the as-ball milled powders were determined by inductively coupled plasma optical (ICP) emission spectrometry. Shimadzu Thermal Analysis System/TA-60WS, using differential scanning calorimeter (DSC), was employed to investigate the thermal stability indexed by the decomposition temperatures of $\mathrm{MgH}_{2}$ and to estimate the activation energy, using the Arrhenius approach with different heating rates of $7,8,9$, and $10{ }^{\circ} \mathrm{C} / \mathrm{min}$. The hydrogenation properties, including absorption/desorption kinetics and cycle-life-time, were investigated via Sievert's method, using PCTPro-2000, provided by Setaram Instrumentation, Caluire, France.

\section{Results}

The XRD pattern of the end-product of $\mathrm{MgH}_{2} / 5.2 \mathrm{TiC} / 4.6 \mathrm{FeCr}$ nanocomposite powders obtained after $50 \mathrm{~h}$ of ball milling is shown in Figure 1 . The powders composed of $\beta-\mathrm{MgH}_{2}$ (PDF file \#: 03-065-3365) and $\gamma-\mathrm{MgH}_{2}$ (PDF file \#: 00-035-1184) phases mixed with fcc-TiC phase (PDF file \#: 00-031-1400). This end-product was significantly contaminated ( 2.3 wt. \%) with bcc-FeCr alloy (PDF file \#: 00-054-0331) introduced to the powders upon using FeCr stainless steel as milling tool. A significant amount of bcc-FeCr was obtained as shown in Figure 1. Moreover, handling the powders outside of the glove box led to a surface oxidation of the powders and the formation of magnesium oxide layers, as indicated by the Bragg-peaks belonging to fcc-MgO phase (PDF file \#: 00-004-0829) shown in Figure 1. Obviously, the as-prepared nanocomposite powders revealed broad Bragg peaks, suggesting the formation of nanocrystalline grains.

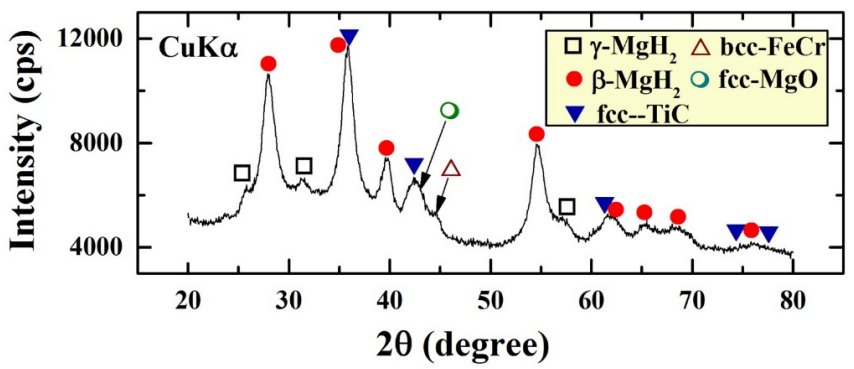

Figure 1. $\mathrm{XRD}$ patterns of $\mathrm{MgH}_{2}$ nanocrystalline powders obtained after $200 \mathrm{~h}$ of $\mathrm{RBM}$ time and then ball-milled with $\mathrm{TiC}$ powders for $50 \mathrm{~h}$. 
The bright field image (BFI) of nanocomposite $\mathrm{MgH}_{2} / 5.2 \mathrm{TiC} / 4.6 \mathrm{FeCr}$ powders obtained after $50 \mathrm{~h}$ of ball milling is displayed in Figure 2a. The powders revealed Moiré-fringes of different phases. This is suggested by the dissimilarity in the interplanar spacing (2d), as shown in Figure 2a. The HRTEM image of the indexed square region shown at the edge of the powders in Figure $2 \mathrm{a}$ is presented in Figure $2 \mathrm{~b}$. The fast Fourier transform (FFT) patterns corresponding to the examined square regions presented in Figure $2 b$ are displayed in Figure $2 c, f$. The atomic array with a long-range ordered structure that was presented in Zone I corresponding to nanocrystalline TiC grain. This was confirmed by the interplanar spacing of $0.247 \mathrm{~nm}$ (Figure 2c) that well matches with fcc-TiC (111). Zone II Figure $2 \mathrm{~b}$ refers to the precipitation of bcc-FeCr contamination, as confirmed by the interplanar spacing of $0.203 \mathrm{~nm}$ for (200), as presented in Figure 2d. Zones III and IV display two individual regions in the $\mathrm{MgH}_{2}$ matrix corresponding to $\beta-\mathrm{MgH}_{2}$ (101) and (111), which are well matching with the interplanar spacing of $0.253 \mathrm{~nm}$ (Figure 2c) and $0.225 \mathrm{~nm}$ (Figure 2f), respectively.

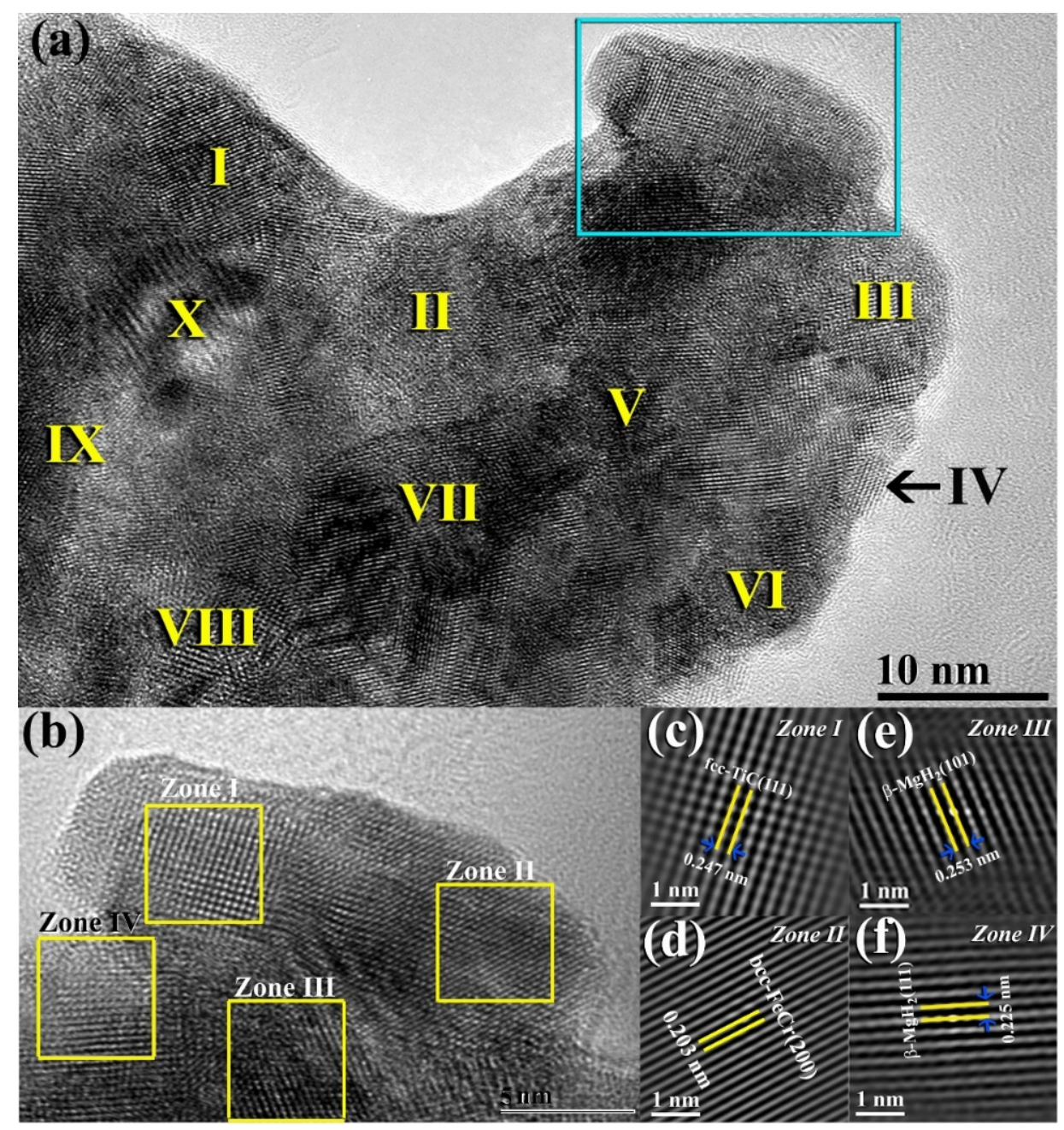

Figure 2. (a) BFI micrograph of as-milled $\mathrm{MgH}_{2} / 5.2 \mathrm{TiC} / 4.6 \mathrm{FeCr}$ nanocomposite powders obtained after $50 \mathrm{~h}$ of ball milling time. The Roman Numerals presented in (a) refer to the points used for EDS local analysis (Table 1). The atomic-resolution TEM image of the squared zone indexed shown in (a) is presented in (b). The FFT lattice images for zones I, II, III, and IV, shown in Figure $2 \mathrm{~b}$ are displayed in (c-f), respectively.

The distribution of $\mathrm{TiC} / \mathrm{FeCr}$ into the $\mathrm{MgH}_{2}$ matrix was examined by intensive EDS local analysis performed at selected points (Roman Numerals symbols shown in Figure 2a) and listed in Table 1 . The results show that the concentration of $\mathrm{TiC} / \mathrm{FeCr}$ is remarkably varied from one region 
to another beyond the nano-level, as shown in Table 1. It is worth mentioning that significant FeCr contamination was evident within those TiC-rich areas (II, IV, VII, X), as shown in Table 1. This is attributed to the existence of high $\mathrm{FeCr}$ contamination content in the as-prepared nanocrystalline $\mathrm{TiC}$ powders. However, a considerable amount of FeCr contamination content existed in the as-prepared $\mathrm{MgH}_{2}$ nanocrystalline powders, as can be seen in the rich Mg-area presented in Table 1 (I, V, VI, and VIII).

Table 1. Local EDS elemental analysis of the points presented in Figure 2a for $\mathrm{MgH}_{2} / 5.2 \mathrm{TiC} / 4.6 \mathrm{FeCr}$ nanocomposite powders obtained after $50 \mathrm{~h}$ of ball milling. The oxygen content introduced to the sample during TEM sample preparations is not included.

\begin{tabular}{ccccccc}
\hline \multirow{2}{*}{ Point } & \multicolumn{7}{c}{ Elements (wt. \%) } \\
\cline { 2 - 7 } & $\mathbf{M g}$ & $\mathbf{T i}$ & $\mathbf{C}$ & $\mathbf{F e}$ & $\mathbf{C r}$ & Total \\
\hline I & 97.03 & 1.60 & 0.38 & 3.42 & 0.57 & 100 \\
II & 15.65 & 40.30 & 10.12 & 29.21 & 4.72 & 100 \\
III & 95.79 & 0.73 & 0.18 & 2.83 & 0.47 & 100 \\
IV & 48.70 & 28.63 & 7.16 & 12.87 & 2.64 & 100 \\
V & 76.03 & 9.82 & 3.96 & 8.26 & 1.93 & 100 \\
VI & 97.29 & 0.88 & 0.22 & 1.38 & 0.23 & 100 \\
VII & 39.70 & 30.57 & 7.16 & 18.93 & 3.64 & 100 \\
VIII & 98.59 & 0.24 & 0.08 & 0.93 & 0.16 & 100 \\
IX & 97.20 & 1.13 & 0.26 & 1.18 & 0.23 & 100 \\
X & 61.2 & 18.65 & 4.83 & 12.79 & 2.53 & 100 \\
\hline
\end{tabular}

In order to get more information about the $\mathrm{TiC} / \mathrm{FeCr}$ distribution embedded into the host $\mathrm{MgH}_{2}$ matrix, STEM-EDS X-ray elemental mapping was performed. Figure 3 presents the images of STEM-(bright field) BF (a), STEM-(dark field) DF (b) and the corresponding EDS chemical mapping for $\mathrm{Mg}(\mathrm{c}), \mathrm{O}(\mathrm{d}), \mathrm{Ti}(\mathrm{e}), \mathrm{C}(\mathrm{f}) \mathrm{Fe}(\mathrm{g})$, and $\mathrm{Cr}(\mathrm{h})$ of an agglomerated powder obtained after $50 \mathrm{~h}$ of the ball milling. The powder had nearly a spherical-like morphology with a size of about $520 \mathrm{~nm}$ in diameter (Figure 3a). Obviously, the powder after this stage of milling had a rough surface topology related to attachment with $\mathrm{TiC}$ nanocrystalline particles (Figure 3b). As a result of SEM sample preparations and handling the powders outside of the glove box, the $\mathrm{MgH}_{2}$ powder (Figure 3c) was oxidized, as indicated by a thin-layer of $\mathrm{MgO}$ coat with a thickness of about $68 \mathrm{~nm}$, as shown in Figure 3c. Nanocrystalline TiC (Figure 3a,e,f) was homogeneously distributed onto the surface of $\mathrm{MgH}_{2}$ powders. The individual $\mathrm{TiC}$ particle size was in the range of $10-20 \mathrm{~nm}$ in diameter, as shown in Figure 3e). However, some agglomerated $\mathrm{TiC}$ particles with apparent sizes ranging between $80 \mathrm{~nm}$ and $220 \mathrm{~nm}$ were bonded onto the $\mathrm{MgH}_{2}$ surfaces, as shown in Figure 3e. The FeCr contamination introduced to the powders upon using steel balls was homogeneously distributed in the $\mathrm{MgH}_{2}$ matrix, as elucidated in Figure $3 \mathrm{~g}$, h. We should emphasize that the concentration of $\mathrm{FeCr}$ contamination was higher in the regions containing TiC-particles when compared with the $\mathrm{MgH}_{2}$-matrix region, as shown in Figure $3 \mathrm{e}-\mathrm{h}$.

The thermal stability of nanocomposite $\mathrm{MgH}_{2} / 5.2 \mathrm{TiC} / 4.6 \mathrm{FeCr}$ powders obtained after $50 \mathrm{~h}$ of the ball milling was investigated by DSC analysis conducted with heating rates $(k)$ of $7,8,9$, and $10{ }^{\circ} \mathrm{C} / \mathrm{min}$ and presented in Figure 4 . All the scans revealed single endothermic events related to the decomposition of $\mathrm{MgH}_{2}$ phase. While the peak height increased proportionally with increasing heating rates, the peak temperatures $\left(T_{\mathrm{p}}\right)$ were significantly shifted to the higher temperature side upon increasing the heating rates from $7^{\circ} \mathrm{C} / \mathrm{min}$ to $10{ }^{\circ} \mathrm{C} / \mathrm{min}$, as shown in Figure 4 . The peak decomposition temperature performed at a heating rate of $10^{\circ} \mathrm{C} / \mathrm{min}$ was $658 \mathrm{~K}\left(385^{\circ} \mathrm{C}\right)$. When comparing this value with that $\left(441^{\circ} \mathrm{C}\right)$ obtained for nanocrystalline $\mathrm{MgH}_{2}$ powders [12], one can say that doping $\mathrm{MgH}_{2}$ with $5.2 \mathrm{wt}$ \% TiC/4.6 wt. \% FeCr powders led to destabilizing the metal hydride phase and decreasing the decomposition temperature by $56{ }^{\circ} \mathrm{C}$. 

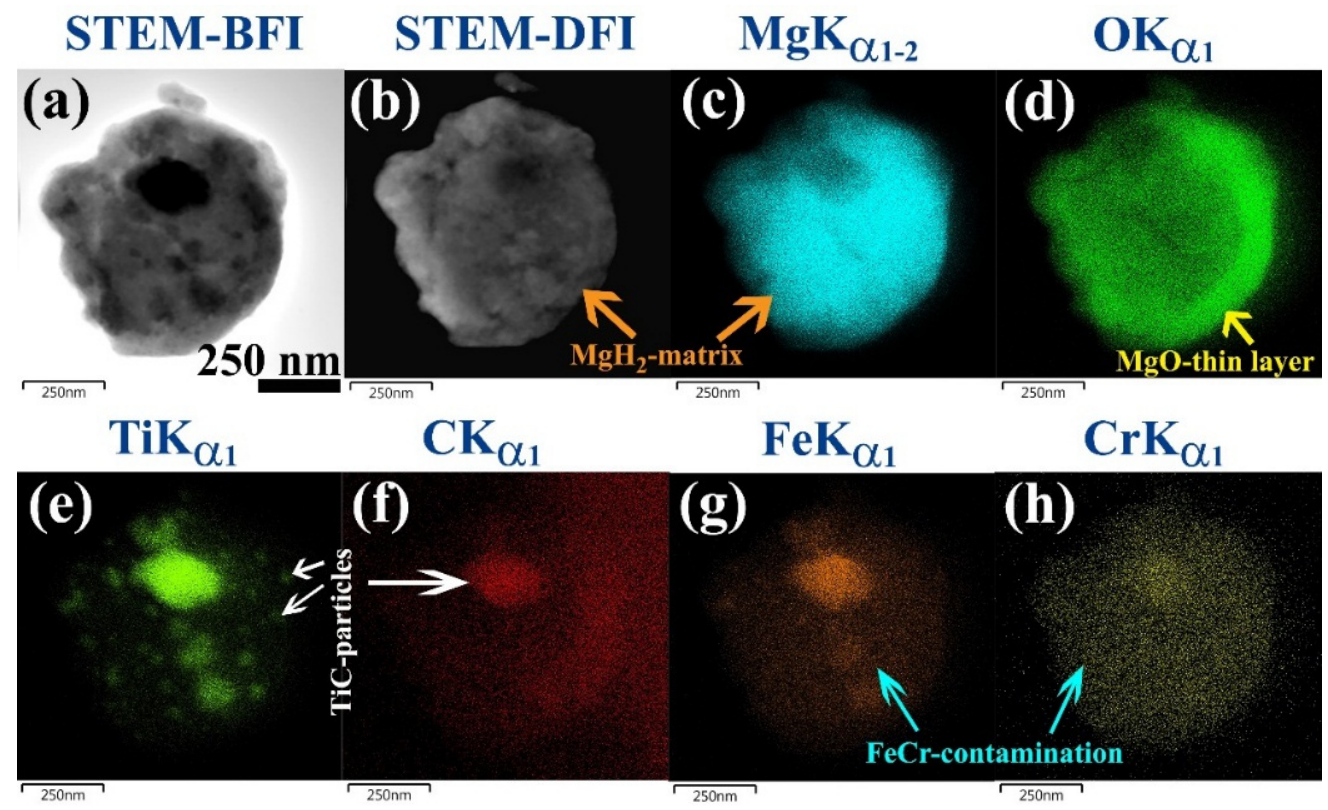

Figure 3. (a) STEM-BF; (b) STEM-DF micrographs and the corresponding X-ray elemental mapping of (c) $\mathrm{Mg}$; (d) $\mathrm{O}$; (e) $\mathrm{Ti}$; (f) $\mathrm{C}$; (g) Fe; and (h) $\mathrm{Cr}$ for aggregated $\mathrm{MgH}_{2} / 5.2 \mathrm{TiC} / 4.6 \mathrm{FeCr}$ nanocomposite powders obtained after $50 \mathrm{~h}$ of ball milling.

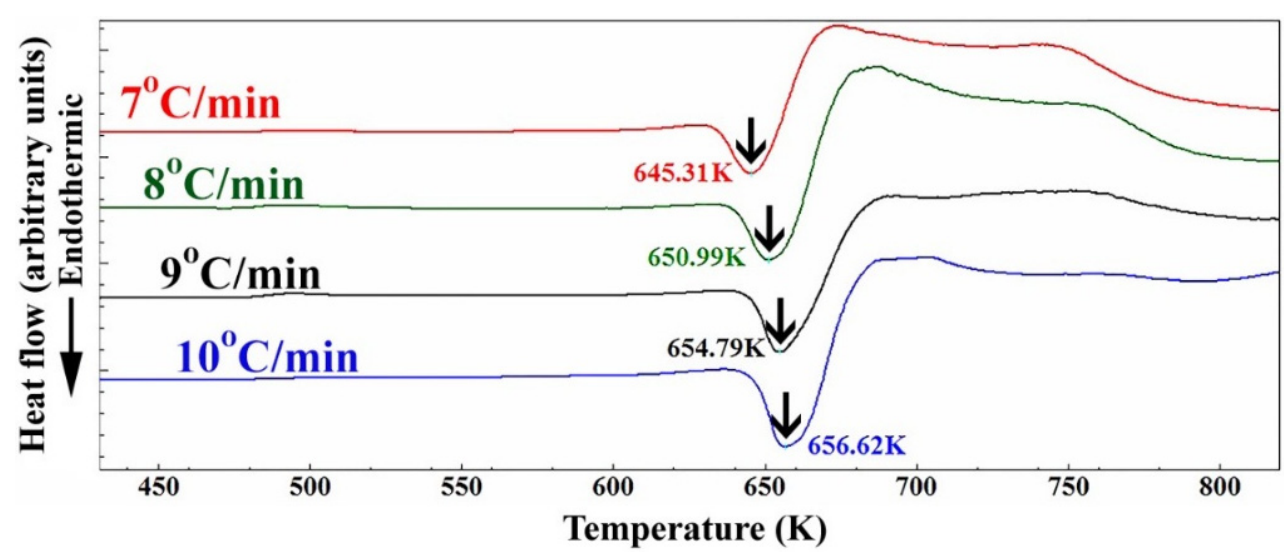

Figure 4. DSC curves achieved at different heating rates $\left(7,8,9\right.$, and $\left.10{ }^{\circ} \mathrm{C} / \mathrm{min}\right)$ of nanocomposite $\mathrm{MgH}_{2} / 5.2 \mathrm{TiC} / 4.6 \mathrm{FeCr}$ powders obtained after $50 \mathrm{~h}$ of milling.

The improved dehydrogenation kinetics in a helium gas atmosphere was investigated by calculating the activation energy $\left(E_{\mathrm{a}}\right)$ of the decomposition reaction. In the present work, the activation energy for dehydrogenation of $\mathrm{MgH}_{2}$ doped with $\mathrm{TiC} / \mathrm{FeCr}$ was calculated according to the Arrhenius Equation:

$$
E_{\mathrm{a}}=-R T \ln (k)
$$

where $k$ is a temperature-dependent reaction rate constant, $R$ is the gas constant, and $T$ is the absolute temperature. The value $E_{\mathrm{a}}$ of the reaction was determined by measuring the decomposition the $T_{\mathrm{p}}$ corresponded to the different heating rates $(k)$ and then plotting $\ln (k)$ versus $1 / T_{\mathrm{p}}$, as shown in Figure 5 . A best fit for the results was calculated by the least-square method. It follows from Figure 5 that all data points lie closely on the same straight line. The $E_{\mathrm{a}}$ of $97.74 \mathrm{~kJ} / \mathrm{mol}$ was obtained from the slope of line $(-E / R)$. This value, which is far below than that one $(146.53 \mathrm{~kJ} / \mathrm{mol})$ calculated for 
pure $\mathrm{MgH}_{2}$ powders [12], indicating a significant improvement of the dehydrogenation kinetics of the $\mathrm{MgH}_{2}$ upon doping with 5.2TiC/4.6FeCr.

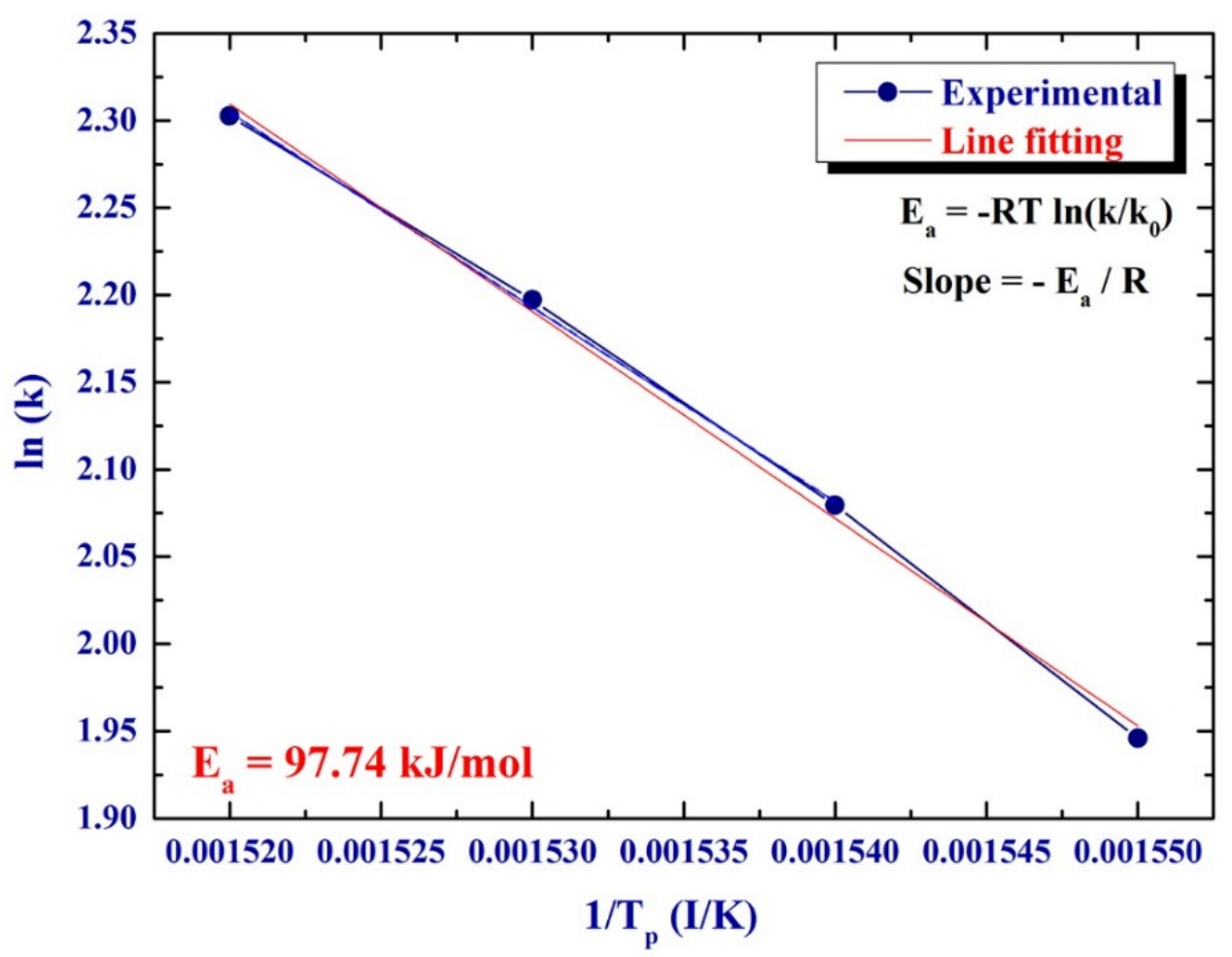

Figure 5. Arrhenius plot displayed the natural logarithmic values of the heating rates $(k)$ versus the inverse of the peak temperature $\left(1 / T_{\mathrm{p}}\right)$ denoted in the DSC curves of Figure 4.

The pressure-composition temperature (PCT) relations of ball-milled $\mathrm{MgH}_{2} / 5.2 \mathrm{TiC} / 4.6 \mathrm{FeCr}$ nanocomposite powders obtained after $50 \mathrm{~h}$ were volumetrically investigated by Sievert's approach at different temperatures of $225,250,275,300,325$, and $350{ }^{\circ} \mathrm{C}$, as elucidated in Figure 6. A single reversible hydrogenation/dehydrogenation cycle was developed for each applied temperature. The presence of clear hydrogenation plateaus can be seen in the range between 0.25 and $5.25 \mathrm{wt} . \% \mathrm{H}_{2}$ at temperatures ranging between 275 and $350^{\circ} \mathrm{C}$, as shown in Figure 6. However, the hydrogen uptake plateau was visible only in the range of $0.25-2.5$ and $0.25-3.25$ wt. $\% \mathrm{H}_{2}$, at temperatures of $225{ }^{\circ} \mathrm{C}$ and $250{ }^{\circ} \mathrm{C}$, respectively. On the other hand, smooth plateaus of hydrogen release were characterized in the whole hydrogen concentrations range $\left(0.25-5.25 \mathrm{wt} . \% \mathrm{H}_{2}\right)$ for all applied temperatures, as presented in Figure 6. The hydrogen equilibrium pressure measurements were used in the present study to investigate the heat of hydrogen absorption, using van't Hoff equation:

$$
\ln \left(\frac{P_{e q}}{P_{o}}\right)=-\frac{\Delta \mathrm{H}}{\mathrm{RT}}+\frac{\Delta \mathrm{S}}{\mathrm{R}}
$$

where $P_{e q}$ is the hydrogen pressure under equilibrium at a given specific temperature, $T ; P_{0}$ is a reference pressure of $1 \mathrm{bar}, R$ is the gas constant $(0.0083145 \mathrm{~J} / \mathrm{K} . \mathrm{mol}) ; \Delta H$ is the molar enthalpy of metal hydride formation $\left(\mathrm{MgH}_{2}\right)$; and $\Delta S$ is the entropy of absorption. Thus, $\Delta H$ can be directly calculated from plotting the natural log of each $P_{\text {eq }}$ point versus the corresponding $1 / T$, as shown in Figure 7a. In the present work, the calculated $\Delta H$ and $\Delta S$ for $\mathrm{MgH}_{2}$ doped with $5.2 \mathrm{TiC} / 4.6 \mathrm{FeCr}$ was $-72.74 \mathrm{~kJ} / \mathrm{mol}$ and $112.79 \mathrm{~J} / \mathrm{mol} \mathrm{H}_{2} / \mathrm{K}$, respectively.

The strength of $\mathrm{Mg}-\mathrm{H}$ bonds, which can be expressed by the enthalpy of decomposition can be calculated by van't Hoff approach, using the equilibrium dehydrogenation pressure in the PCT measurements. A van't Hoff plot illustrating the relationship between $\ln (P)$ and $1 / T$ for the 
decomposition of $\mathrm{MgH}_{2}$ powders doped with $5.2 \mathrm{TiC} / 4.6 \mathrm{FeCr}$ is shown in Figure $7 \mathrm{~b}$. Both of $\Delta H$ and $\Delta S$ were directly calculated from the slope of the curve presented in Figure $7 \mathrm{~b}$ and found to be $76.76 \mathrm{~kJ} / \mathrm{mol}$ and $119.15 \mathrm{~J} / \mathrm{mol} \mathrm{H}_{2} / \mathrm{K}$, respectively. Comparing these values with those reported by Reilly $\left(77.4 \mathrm{~kJ} / \mathrm{mol}, 138.3 \mathrm{~J} / \mathrm{mol} \mathrm{H}_{2} / \mathrm{K}\right)$ [22], and Klose $\left(81.86 \mathrm{~kJ} / \mathrm{mol}, 146.1 \mathrm{~J} / \mathrm{mol} \mathrm{H}_{2} / \mathrm{K}\right)$ [23], one can say that long-term ball milling led to the formation of homogeneous nanocomposite $\mathrm{MgH}_{2} / 5.2 \mathrm{TiC} / 4.6 \mathrm{FeCr}$ powders, destabilizing the chemically stable phase of $\mathrm{MgH}_{2}$, implied by the obvious increase in the $\Delta H$ of decomposition. Until recently, it was believed that $\Delta S$ has a constant value of about $130 \mathrm{~J} / \mathrm{mol} \mathrm{H}_{2} / \mathrm{K}$ [24]. It has been suggested by Zhao-Karger et al. [24] that $\Delta S$ of the dehydrogenation process can be varied based on the $\mathrm{MgH}_{2}$ particle size. Based on the ab initio Hartree-Fock and density functional theory calculations shown by Wagemans et al. [25], magnesium hydride becomes less stable with decreases in the cluster size to less than 20 atoms. Accordingly, and based on that study, the $\Delta H$ of hydrogen desorption decreases significantly when the grain size is smaller than $1.3 \mathrm{~nm}$ [25].

Figure 8 displays the STEM/BF image of the ball-milled nanocomposite sample after the PCT hydrogenation/dehydrogenation measurements under hydrogen gas pressure and temperatures ranging between 0 and 10 bar, and 225 and $350^{\circ} \mathrm{C}$, respectively. Obviously, the sample maintained its nanocrystalline structure ranging between 18 and $67 \mathrm{~nm}$ for $\mathrm{MgH}_{2}$ matrix (light gray-scale particles) and 8 and $27 \mathrm{~nm}$ for TiC (dark particles), as shown in Figure 8. We should emphasize that the as-prepared ultrafine powders in the present study with their nanostructured grains facilitated better hydrogen desorption and shortened the diffusion distance required to accomplish a complete dehydrogenation process. In addition, $\mathrm{TiC}$ refractory nanoparticles acted as grain growth inhibitors maintaining the $\mathrm{MgH}_{2}$ particles, especially when the samples were subjected to the high temperature side $\left(300-350{ }^{\circ} \mathrm{C}\right)$ during the PCT analysis.

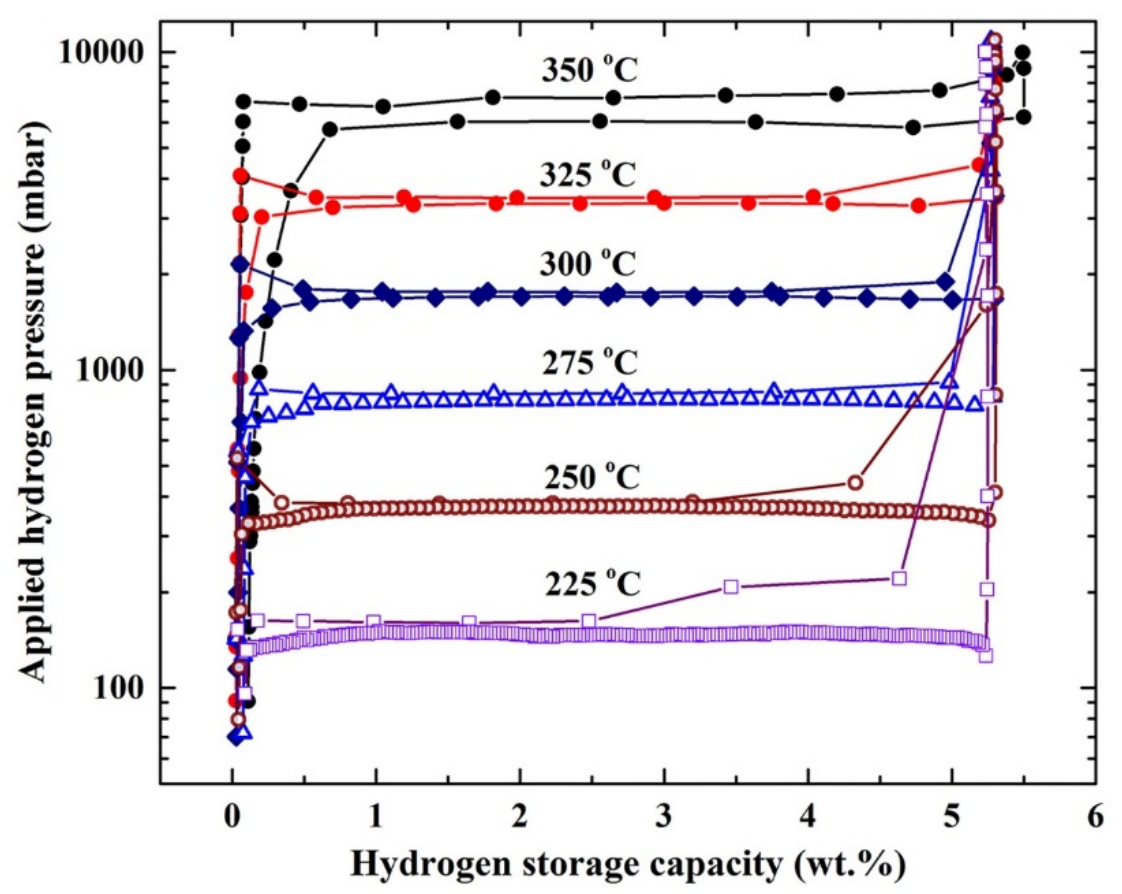

Figure 6. Pressure-composition-temperature (PCT) curves of ball-milled $\mathrm{MgH}_{2} / 5.2 \mathrm{TiC} / 4.6 \mathrm{FeCr}$ nanocomposite powders obtained after $50 \mathrm{~h}$ at different temperatures of 225, 250, 275, 300, 325, and $350{ }^{\circ} \mathrm{C}$. 

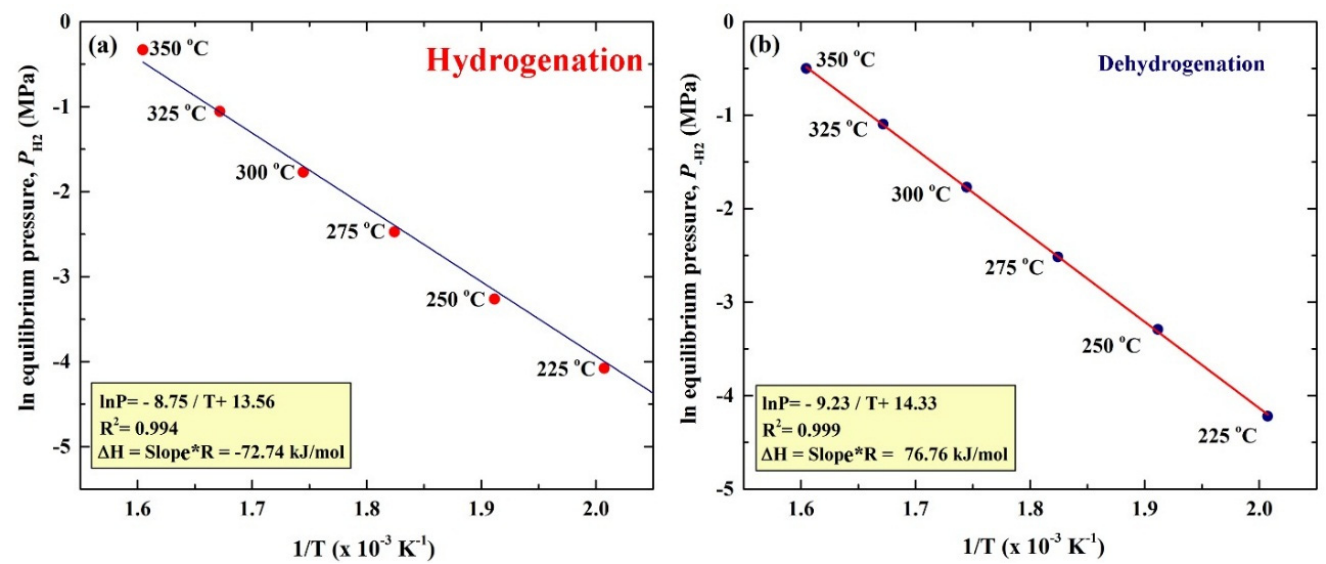

Figure 7. van't Hoff plot of the plateaus shown in Figure 6 for the (a) hydrogenation, and (b) dehydrogenation of ball-milled $\mathrm{MgH}_{2} / 5.2 \mathrm{TiC} / 4.6 \mathrm{FeCr}$ nanocomposite powders obtained after $50 \mathrm{~h}$.

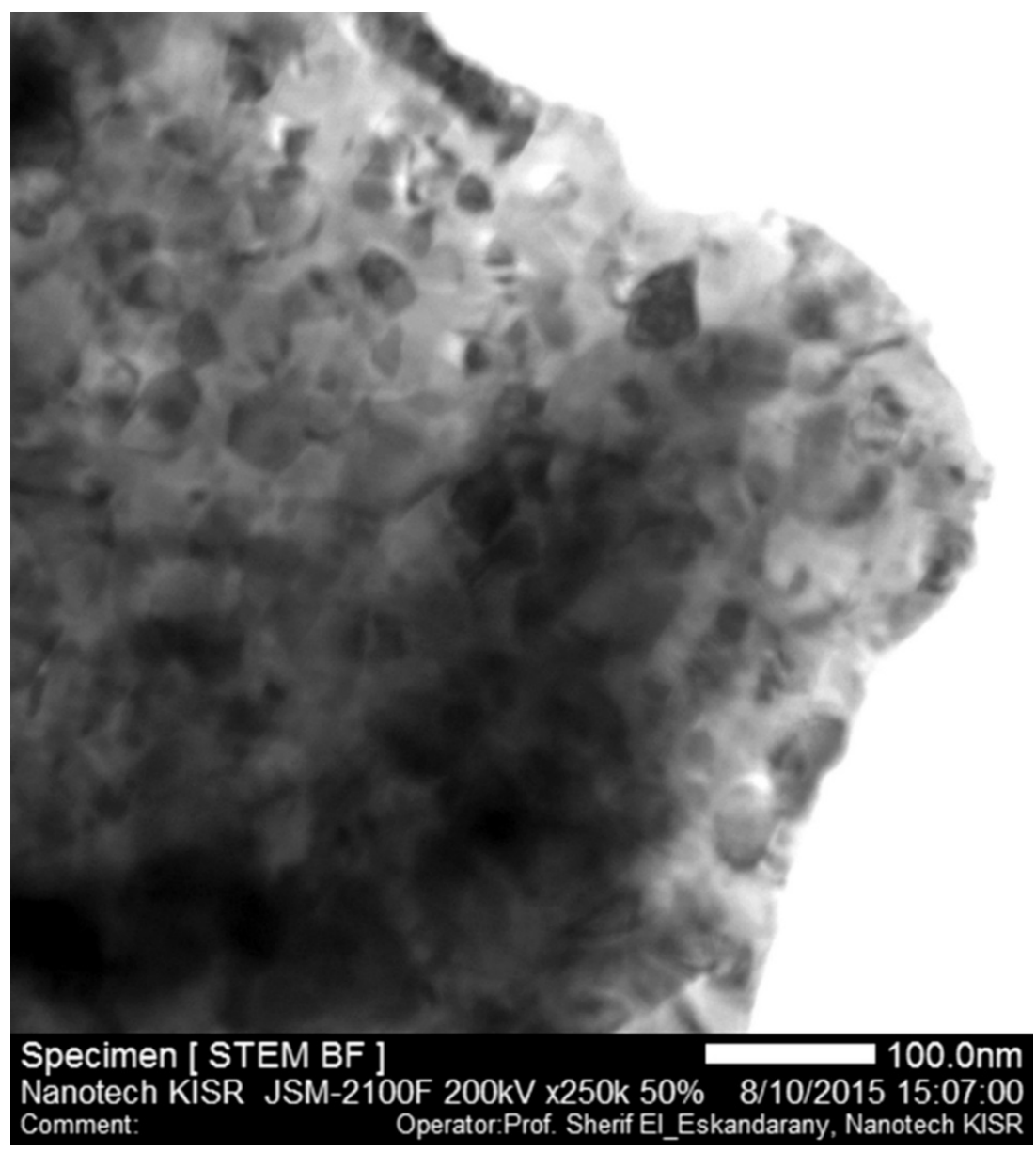

Figure 8. STEM/BF image of ball-milled $\mathrm{MgH}_{2} / 5.2 \mathrm{TiC} / 4.6 \mathrm{FeCr}$ nanocomposite sample after achieving the PCT hydrogenation/dehydrogenation measurements under hydrogen gas pressure and temperatures ranging between 0 and $10 \mathrm{bar}$, and 225 and $350{ }^{\circ} \mathrm{C}$, respectively.

Figure 9 displays the temperature effect on the hydrogen absorption (a) and consequence desorption $(b, c)$ kinetics of nanocomposite $\mathrm{MgH}_{2} / 5.2 \mathrm{TiC} / 4.6 \mathrm{FeCr}$ powders obtained after $50 \mathrm{~h}$ of 
the ball milling. In general, the synthesized nanocomposite powders showed excellent potential for absorbing hydrogen gas in a short time at temperatures ranging from 250 to $275^{\circ} \mathrm{C}$ under pressure ranging from $100 \mathrm{mbar}$ to $8 \mathrm{bar}$, as shown in Figure 9a. After $1 \mathrm{~min}$, the powders examined at 250 and $275{ }^{\circ} \mathrm{C}$ were able to uptake 3.66 and $4.55 \mathrm{wt} . \% \mathrm{H}_{2}$, respectively as elucidated in Figure 9a. After $11.2 \mathrm{~min}$ of the absorption, the sample examined at $275^{\circ} \mathrm{C}$ reached its saturated value with hydrogen storage reaching $5.51 \mathrm{wt}$. \%. In contrast, $19.2 \mathrm{~min}$ was required for the sample examined at $250{ }^{\circ} \mathrm{C}$ to absorb 5.41 wt. $\% \mathrm{H}_{2}$, as shown in Figure 9a.
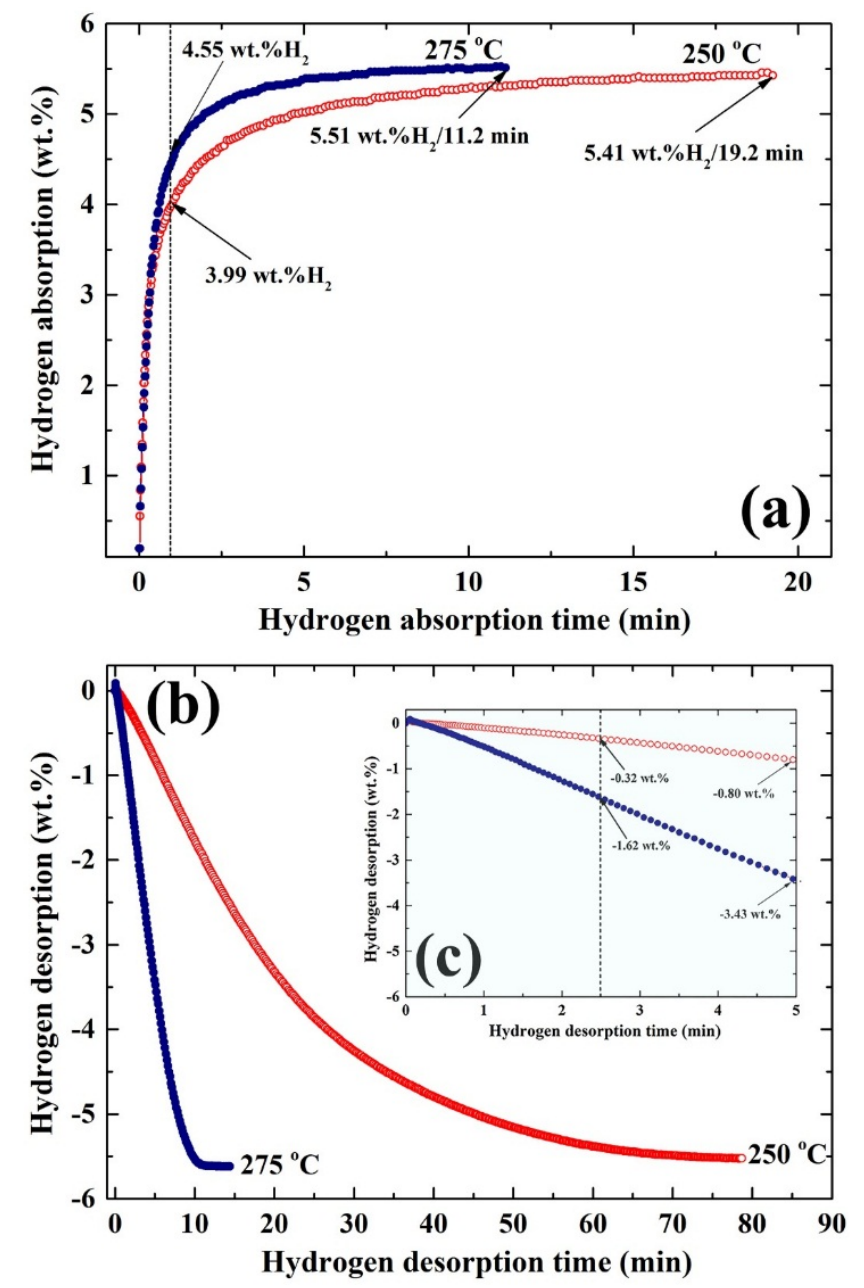

Figure 9. Effect of temperature and time on the (a) hydrogenation; and (b) dehydrogenation kinetics of nanocomposite $\mathrm{MgH}_{2} / 5.2 \mathrm{TiC} / 4.6 \mathrm{FeCr}$ powders obtained after ball milling for $50 \mathrm{~h}$. The dehydrogenation kinetics measured at $250{ }^{\circ} \mathrm{C}$ (open symbols) and $275{ }^{\circ} \mathrm{C}$ (closed symbols) after $5 \mathrm{~min}$ of desorption are presented in Figure 9c.

The corresponding desorption kinetics of the nanocomposite powders investigated at $250{ }^{\circ} \mathrm{C}$ and $275{ }^{\circ} \mathrm{C}$ are shown in Figure $9 \mathrm{~b}$,c. The powders examined at $275^{\circ} \mathrm{C}$ showed excellent desorption kinetics, indexed by the relatively short time $(\sim 10 \mathrm{~min})$ required to release about $5.51 \mathrm{wt}$. \% of hydrogen, as shown in Figure 9b. The sample examined at this temperature desorbed $1.62 \mathrm{wt} . \%$ of hydrogen within a short desorption time of $2.5 \mathrm{~min}$, as shown in Figure 9c. At this applied temperature, the sample released about $3.43 \mathrm{wt}$. \% of its hydrogen storage capacity after $5 \mathrm{~min}$ of desorption, as elucidated in Figure 7c. In contrast to such fast desorption kinetics achieved at $275^{\circ} \mathrm{C}$, the sample examined at $250{ }^{\circ} \mathrm{C}$ showed a slow dehydrogenation behavior, indexed by the long time required to release its full hydrogen content ( $\sim 5.5 \mathrm{wt} . \%), 79 \mathrm{~min}$, as shown in Figure $9 \mathrm{~b}$. After 2.5 and $5 \mathrm{~min}$ of desorption conducted at $250{ }^{\circ} \mathrm{C}$ (Figure 9c), the sample was unable to release more than 
0.32, and $0.80 \mathrm{H}_{2}$ wt. \%, respectively, as presented in Figure 9c. Aside from the particle size effect on the $\Delta H$ and $\Delta S$ of hydrogen desorption for $\mathrm{MgH}_{2}$, the dehydrogenation temperature decreased from $400{ }^{\circ} \mathrm{C}$ in bulk $\mathrm{MgH}_{2}$ to be $250-275^{\circ} \mathrm{C}$, when the crystallite size of $\mathrm{MgH}_{2}$ was less than $10 \mathrm{~nm}$ in diameter (Figure 2a).

Apart from the fast kinetics of hydrogenation/dehydrogenations characterizations shown by $\mathrm{MgH}_{2} / 5.2 \mathrm{TiC} / 4.6 \mathrm{FeCr}$ ternary system, the cyclic-reversibility of the fabricated nanocomposite powders examined at $275{ }^{\circ} \mathrm{C}$ under repeated hydrogenation/dehydrogenation pressure of $0 / 8$ bar was investigated. Figure 10 shows the cycle-life-time performed at $275{ }^{\circ} \mathrm{C}$ for the nanocomposite powders obtained after $50 \mathrm{~h}$ of ball milling. Obviously, this new nanocomposite system exhibits excellent cyclic-reversible properties, indexed by its high cyclic stability without failure, even after about 682 h (679 cycles), as shown in Figure 10. Comparing the number of cycles achieved at $275^{\circ} \mathrm{C}$ by this nanocomposite system with those performed in $\mathrm{MgH}_{2} / \mathrm{Mn}_{3.6} \mathrm{Ti}_{2.4}, 1000$ cycles $/ 275{ }^{\circ} \mathrm{C}$ [16],

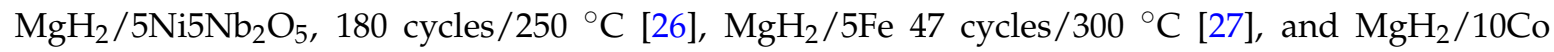
$350{ }^{\circ} \mathrm{C}$ [25] systems, one can consider the $\mathrm{MgH}_{2} / \mathrm{TiC} / \mathrm{FeCr}$ system as one of the most stable and capable $\mathrm{MgH}_{2}$-based nanocomposite systems used for hydrogen storage applications.

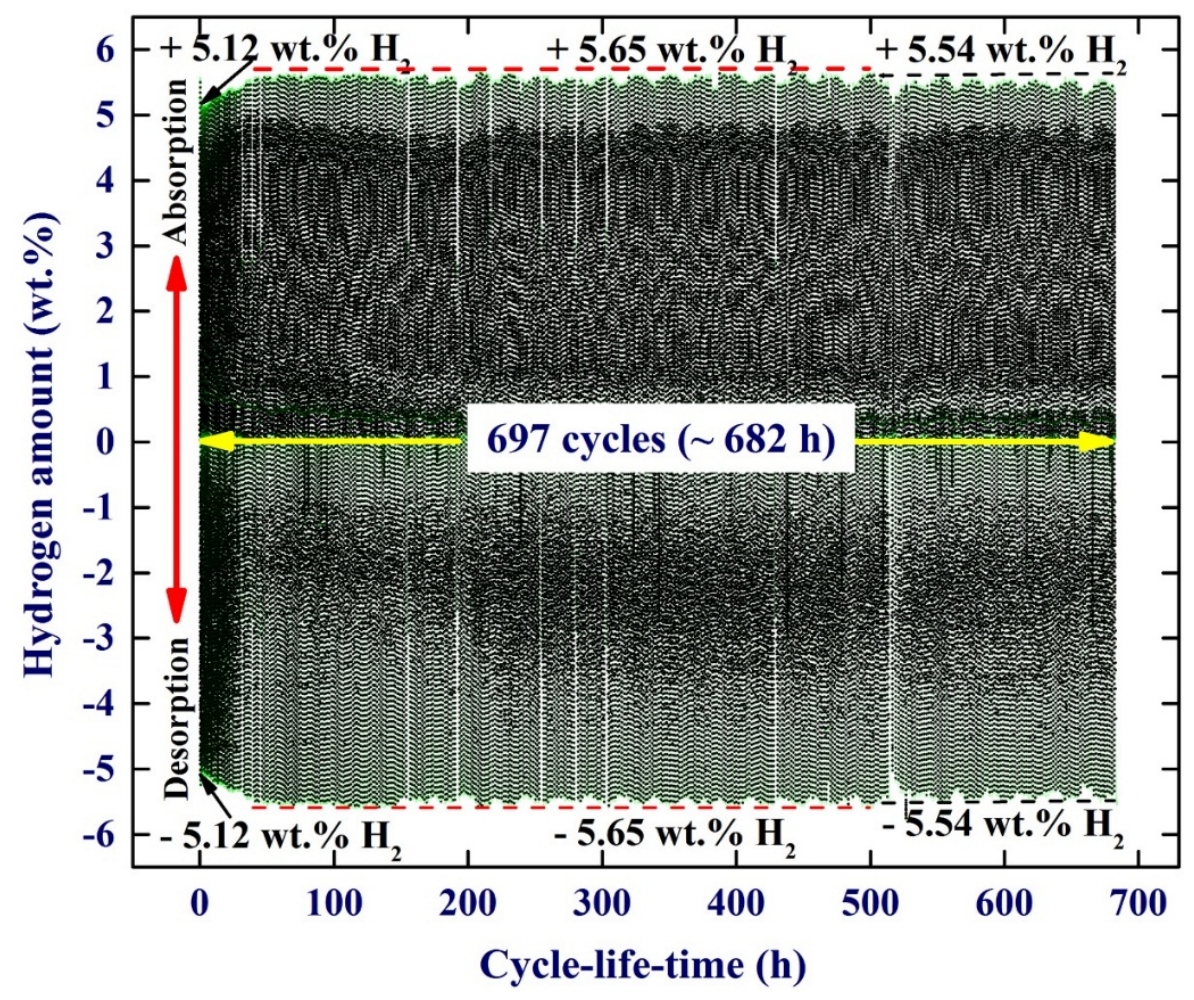

Figure 10. (a) Hydrogenation and consequent dehydrogenation curves of 697 complete cycles performed within $682 \mathrm{~h}$ for nanocomposite $\mathrm{MgH}_{2} / 5.2 \mathrm{TiC} / 4.6 \mathrm{FeCr}$ powders obtained after $50 \mathrm{~h}$ of ball milling. The hydrogen absorption and desorption processes were achieved at a constant temperature of $275^{\circ} \mathrm{C}$ with an applied pressure of $100 \mathrm{mbar} / 8$ bar.

\section{Conclusions}

Nanocrystalline $\mathrm{MgH}_{2}$ powders were synthesized by reactive ball milling of pure $\mathrm{Mg}$ powders, using a high-energy ball mill operated at $250 \mathrm{rpm}$ under 50 bar of hydrogen atmosphere. The as-synthesized $\mathrm{MgH}_{2}$ powders obtained after $200 \mathrm{~h}$ of ball milling were contaminated by about 2.2 wt. \% of FeCr. The powders were doped with $\mathrm{TiC}$ ultrafine powders, which were already contaminated with $2.4 \mathrm{wt}$ \% FeCr, and then ball milled for $50 \mathrm{~h}$. Significant improvements in the hydrogenation/dehydrogenation kinetics of $\mathrm{MgH}_{2}$ doped with 5.2TiC/4.6FeCr were achieved. Such improvements are attributed to the presence of FeCr content that played an important role in 
splitting the $\mathrm{H}_{2}$ molecules and facilitating proper hydrogen diffusion into the $\mathrm{Mg}$ matrix. In addition, ball milling the $\mathrm{MgH}_{2}$ powders with refractory TiC nanopowders led to further grain refining of the metal hydride phase, enabling fast hydrogen absorption/desorption processes. Moreover, the hard $\mathrm{TiC}$ phase inhibited grain growth, allowing to maintain the nanocrystallinity of $\mathrm{MgH}_{2}$ powders during repeated hydrogenation/dehydrogenation cycles that extended to 697 cycles without failure or degradation.

Acknowledgments: Appreciation is extended to His Highness the Amir of the State of Kuwait, Sheikh Sabah Al-Ahmad Al-Jaber Al-Sabah through the Kuwait Foundation for the Advancement of Sciences (KFAS) for the partial financial support this study under a contract number: 2010-550401. The financial support received by the Kuwait Government through the Kuwait Institute for Scientific Research for purchasing the equipment used in the present work, using the budget dedicated for the project led by the first author (P-KISR-06-04) of Establishing Nanotechnology Center in KISR is highly appreciated.

Author Contributions: M. Sherif El-Eskandarany conceived and designed, contributed the TiC sample preparations, XRD-structural analysis, FETEM/STEM/EDS, FESEM, thermal stability, experiments of and wrote the paper. Ehab Shaban performed the $\mathrm{MgH}_{2}$ and $\mathrm{MgH}_{2} / \mathrm{TiC}$ sample preparations, achieving the calculated the tackling the kinetics measurements and analysis experiments; M. Sherif El-Eskandarany and Ehab Shaban analyzed the data; performed the measurements and analysis related to van't Hoff plot, and shared writing the experimental procedure of the paper.

Conflicts of Interest: The authors declare no conflict of interest.

\section{References}

1. Shao, H.; Xin, G.; Zheng, J.; Li, X.; Akiba, E. Nanotechnology in Mg-based materials for hydrogen storage. Nano Energy 2012, 1, 590-601. [CrossRef]

2. Calka, A. Formation of titanium and zirconium nitrides by mechanical alloying. Appl. Phys. Lett. 1991, 59, 1568-1570. [CrossRef]

3. El-Eskandarany, M.S.; Sumiyama, K.; Aoki, K.; Suzuki, K. Reactive ball mill for solid state synthesis of metal nitrides powder. Mater. Sci. Forum. 1992, 88, 801-808. [CrossRef]

4. El-Eskandarany, M.S. Mechanical alloying Nanotechnology, Materials Science and Powder Metallurgy, 2nd ed.; Elsevier: Oxford, UK, 2015.

5. El-Eskandarany, M.S.; Omori, M.; Konno, T.J.; Sumiyama, K.; Hirai, T.; Suzuki, K. Synthesis of full-density titanium nitride compacts by plasma activated sintering of mechanically reacted powder. Met. Trans. A. 1998, 29, 1973-1981. [CrossRef]

6. Varin, R.A.; Czujko, T.; Wronski, Z.S. Nanomaterials for Solid State Hydrogen Storage; Springer Science+Business Media, LLC: New York, NY, USA, 2009.

7. Momirlan, M.; Veziroglu, T.N. The properties of hydrogen as fuel tomorrow in sustainable energy system for a cleaner planet. Int. J. Hydrog. Energy 2005, 30, 795-805. [CrossRef]

8. Jain, I.P.; Lal, C.; Jain, A.I. Hydrogen storage in Mg: A most promising material. Int. J. Hydrog. Energy 2010, 35, 5133-5144. [CrossRef]

9. Principi, G.; Agresti, F.; Maddalena, A.; Lo, R.S. The problem of solid state hydrogen storage. Energy 2009, 34, 2087-2091. [CrossRef]

10. Pukazhselvan, D.; Kumar, V.; Singh, S.K. High capacity hydrogen storage: Basic aspects, new developments and milestones. Nano Energy 2012, 1, 566-589. [CrossRef]

11. Varin, R.A.; Czujko, T.; Wronski, Z. Particle size, grain size and $\gamma-\mathrm{MgH}_{2}$ effects on the desorption properties of nanocrystalline commercial magnesium hydride processed by controlled mechanical milling. Nanotechnology 2006, 17, 38-56. [CrossRef]

12. El-Eskandarany, M.S.; Shaban, E.; Al-Halaili, B. Nanocrystalline $\beta-\gamma-\beta$ cyclic phase transformation in reacted ball milled $\mathrm{MgH}_{2}$ powders. Int. J. Hydrog. Energy 2014, 39, 12727-12740. [CrossRef]

13. Shang, C.X.; Bououdina, M.; Song, Y.; Guo, Z.X. Mechanical alloying and electronic simulations of $\left(\mathrm{MgH}_{2}+\mathrm{M}\right)$ systems $(\mathrm{M}=\mathrm{Al}, \mathrm{Ti}, \mathrm{Fe}, \mathrm{Ni}, \mathrm{Cu}$ and $\mathrm{Nb})$ for hydrogen storage. Int. J. Hydrog. Energy 2004, 29, 73-80. [CrossRef]

14. Zhou, C.; Fang, Z.Z.; Ren, C.; Li, J.; Lu, J. Effect of Ti intermetallic catalysts on hydrogen storage properties of magnesium hydride. J. Phys. Chem. C 2014, 118, 11526-11535. [CrossRef] 
15. Yu, X.B.; Guo, Y.H.; Yang, H.; Wu, Z.; Grant, D.M.; Walker, G.S. Improved hydrogen storage in magnesium hydride catalyzed by nanosized $\mathrm{Ti}_{0.4} \mathrm{Cr}_{0.15} \mathrm{Mn}_{0.15} \mathrm{~V}_{0.3}$ Alloy. J. Phys. Chem. C 2009, 113, 5324-5328. [CrossRef]

16. El-Eskandarany, M.S.; Al-Matrouk, H.; Shaban, E.; Al-Duweesh, A. Effect of mechanically-induced solid-state doping time on the morphology and hydrogenation cyclability of $\mathrm{MgH}_{2} / 7 \mathrm{Mn}_{3.6} \mathrm{Ti}_{2.4}$ nanocomposite powders. Int. J. Hydrog. Energy 2015, 40, 10139-10149. [CrossRef]

17. Fan, M.Q.; Liu, S.S.; Zhang, Y.; Zhang, J.; Sun, L.-X.; Xu, F. Superior hydrogen storage properties of $\mathrm{MgH}_{2}-10$ wt. \% TiC composite. Energy 2010, 35, 3417-3421. [CrossRef]

18. Porcu, M.; Petford-Long, A.K.; Sykes, J.M. TEM studies of $\mathrm{Nb}_{2} \mathrm{O}_{5}$ catalyst in ball-milled $\mathrm{MgH}_{2}$ for hydrogen storage. J. Alloys Compd. 2005, 398, 341-346. [CrossRef]

19. Chen, J.; Fu, H.; Xiong, Y.; Xu, J.; Zheng, J.; Li, X. $\mathrm{MgCl}_{2}$ promoted hydrolysis of $\mathrm{MgH}_{2}$ nanoparticles for highly efficient $\mathrm{H}_{2}$ generation. Nano Energy 2014, 10, 337-343. [CrossRef]

20. Ismail, M. Effect of $\mathrm{LaCl}_{3}$ addition on the hydrogen storage properties of $\mathrm{MgH}_{2}$. Energy 2015, 79, $177-182$. [CrossRef]

21. El-Eskandarany, M.S.; Al-Hazza, A. Mechanically induced self-propagating reaction and consequent consolidation for the production of fully dense nanocrystalline $\mathrm{Ti}_{55} \mathrm{C}_{45}$ bulk material. Mater. Charact. 2014, 9, 92-100. [CrossRef]

22. Reilly, J.J.; Wiswall, R.H. The reaction of hydrogen with alloys of magnesium and nickel and the formation of $\mathrm{Mg}_{2} \mathrm{Ni}$. Ibid. Chem. 1968, 7, 2254-2256.

23. Klose, W.; Stuke, V. Investigation of the thermodynamic equilibrium in the hydrogen-magnesiummagnesium hydride system. Int. J. Hydrog. Energy. 1995, 20, 309-316. [CrossRef]

24. Zhao-Karger, Z.; Hu, J.; Roth, A.; Wang, D.; Kubel, C.; Lohstroh, W.; Fichtner, M. Altered thermodynamic and kinetic properties of $\mathrm{MgH}_{2}$ infiltrated in microporous scaffold. Chem. Commun. 2010, 46, 8353-8355. [CrossRef] [PubMed]

25. Wagemans, R.W.P.; van Lenthe, J.H.; de Jongh, P.E.; van Dillen, A.J.; de Jong, K.P. Hydrogen storage in magnesium clusters: Quantum chemical study. J. Am. Chem. Soc. 2005, 127, 16675-16680. [CrossRef] [PubMed]

26. El-Eskandarany, M.S.; Ehab, S.; Al-Shemmiri, A. Integrated $\mathrm{Ni} / \mathrm{Nb}_{2} \mathrm{O}_{5}$ nanocatalytic agent dose for improving the hydrogenation/dehydrogenation kinetics of reacted ball milled $\mathrm{MgH}_{2}$ powders. Int. J. Hydrog. Energy 2014, 39, 21097-21106. [CrossRef]

27. Lima, G.F., Jr.; Jorge, A.M.; Leiva, D.R.; Kiminami, C.S.; Bolfarini, C.; Botta, W.J. Severe plastic deformation of Mg-Fe powders to produce Bulk Hydrides. J. Phys. Conf. Ser. 2009, 144. [CrossRef]

(C) 2015 by the authors; licensee MDPI, Basel, Switzerland. This article is an open access article distributed under the terms and conditions of the Creative Commons by Attribution (CC-BY) license (http:/ / creativecommons.org/licenses/by/4.0/). 